\title{
Elogio à diversidade: globalização, pluralismo jurídico e direito das culturas* $^{*}$
}

\author{
Compliment to diversity: \\ globalization, legal pluralism and \\ culture's right
}

Sérgio Ricardo Fernandes de Aquino ${ }^{1}$ Neuro José Zambam²

Recebido em: 23/03/2016.

Aprovado em: 20/05/2016.

1 Doutor e Mestre em Ciência Jurídica pela Universidade do Vale do Itajaí - UNIVALI. Professor Permanente do Programa de Pós-Graduação Stricto Sensu - Mestrado - em Direito da Faculdade Meridional - IMED. Pesquisador da Faculdade Meridional. Membro do Grupo de Estudos Interdisciplinares em Ciências Humanas, Contingência e Técnica na linha de pesquisa Norma, Sustentabilidade e Cidadania da Universidade Federal do Maranhão - UFMA. Membro associado do Conselho Nacional de Pós-Graduação em Direito - CONPEDI. Coordenador do Grupo de Pesquisa em Ética, Cidadania e Sustentabilidade no Programa de Mestrado em Direito (PPGD) da Faculdade Meridional - IMED. Membro do Grupo de Pesquisa sobre Direitos Culturais e Pluralismo Jurídico da Faculdade Meridional - IMED. Membro do Grupo de Pesquisa sobre Transnacionalismo e Circulação de Modelos Jurídicos da Faculdade Meridional - IMED. Vice-líder no Centro Brasileiro de pesquisa sobre a teoria da Justiça de Amartya Sen. Membro da Associação Brasileira de Ensino de Direito - ABEDi. Membro do Grupo de Pesquisa em Direito Empresarial e Sustentabilidade, do Instituto Blumenauense de Ensino Superior.

2 Pós-doutor em Filosofia na Universidade do Vale do Rio dos Sinos - UNISINOS. Doutor em Filosofia pela PUCRS. Professor do Programa de Pós-graduação em Direito da Faculdade Meridional - IMED - Mestrado. Professor do Curso de Direito (graduação e especialização) da Faculdade Meridional - IMED de Passo Fundo. Membro do Grupo de Trabalho, Ética e cidadania da ANPOF (Associação Nacional dos Programas de Pós-graduação em Filosofia). Pesquisador da Faculdade Meridional. Coordenador do Grupo de Pesquisa: Multiculturalismo, minorias, espaço público e sustentabilidade. Líder do Grupo de Estudo, Multiculturalismo e pluralismo jurídico. Líder do Centro brasileiro de pesquisa sobre Amartya Sen: interfaces com direito, políticas de desenvolvimento e democracia.

\section{Resumo}

Conviver, especialmente num cenário global multicultural, é um exercício de perene reconhecimento acerca daquilo que aperfeiçoa os significados jurídicos e democráticos do Estado-nação. A pluralidade de (micro)territórios, as formas de organização da vida cotidiana demonstram a existência de outros lugares além do Estado para se constituir uma paz duradoura, não obstante suas adversidades diárias. O Objetivo geral deste estudo é determinar a importância do cenário multicultural na medida em que evidencia outros espaços de diálogos e resolução de conflitos além daqueles impostos pelo Estado. O método de abordagem utilizado é o Indutivo. Como parte das conclusões, é impossível, num cenário global, ignorar como os cenários multiculturais contribuem para a melhoria de vida dos povos, de seus mecanismos institucionais e jurídicos, bem como do reconhecimento transfronteiriço à Dignidade Humana.

Palavras-chave: Direito das culturas. Pluralismo jurídico. Globalização. Multiculturalismo.

\section{Abstract}

To live together, especially in a global and multicultural scenario is an usual exercise of recognition about what perfects the legal and democratic significance of the nation-state. The plurality of (micro) territories, forms of organization of everyday life demonstrates the existence of other places beyond the State to establish a lasting peace, despite their daily adversities. The main objective of this study is to determine the importance of multicultural scenarios in that it shows other spaces of dialogue and conflict resolution in addition to those imposed by the State. The method used is the Inductive. As part of the conclusions, it is impossible in a global scene, ignore as the multicultural phenomenum improves the lives of people, their institutional and legal mechanisms, as well as cross-border recognition of human dignity.

Keywords: Past. Crimes against humanity. Genocide. Slavery. Human trafficking. Culture's law. Legal pluralismo. Globalization. Multiculturalism. 


\section{Considerações iniciais}

A capacidade de conviver com concepções de mundo divergentes e por vezes contraditórias, assim como com as suas respectivas práticas, são alguns dos desafios e compromissos da nossa época.

A integração social é uma das características da humanidade. Desde os primórdios, as comunidades se fundem segundo interesses variados, a formação das famílias congrega pessoas com valores diferentes, a conquista de povos gera sociedades com suas especificidades, a troca de produtos modifica hábitos tradicionais e outras ações que perfazem inúmeras fases da ação humana e sua organização.

$\mathrm{O}$ atual período, fruto de inúmeros fatores de ordem política e econômica ${ }^{3}$, experimentou uma transformação sem precedentes, especificamente pela aproximação de povos e culturas e pela completa modificação das relações interpessoais.

A humanidade nunca esteve tão próxima e suas características conhecidas e evidenciadas, principalmente, pela modernização dos meios de comunicação e outros mecanismos de integração. As redes sociais, por exemplo, oferecem a possibilidade de as pessoas dialogarem sem se conhecerem. $\mathrm{Na}$ área de relacionamento, estão conectados contatos de países e localidades diferentes e distantes que interagem com facilidade e com recursos inimagináveis até um período recente.

As ciências, as instituições, as pessoas e os demais atores sociais respondem a esse movimento de conjunturas, atualizando suas formas de compreensão, atuação e organização.

A realidade cada vez mais dinâmica e plural impulsiona o conjunto da sociedade para, de um lado, reafirmar os seus valores mais caros em permanente diálogo com uma nova dinâmica e, de outro, impulsionar formação de novas referências para contextos com outras exigências.

Essa reflexão está integrada ao grupo de pesquisa Multiculturalismo e Pluralismo Jurídico e visa esclarecer a importância de uma compreensão atualizada da diversidade humana como uma realidade do cotidiano e integrada ao espaço democrático em que ocorre o exercício da convivência com a pluralidade de ideias, comporta-

3 GIAMBIAGI, Fabio; BARRO, Octavio de. Brasil globalizado. 3. ed. Rio de Janeiro: Elsevier, 2008. mentos e objetivos, e os processos de decisão e participação.

O debate sobre o Direito das Culturas é representativo dos desafios que as sociedades democráticas precisam assimilar neste período histórico. Não se trata, apenas, de afirmar a necessidade de garantir direitos, seja no âmbito jurídico seja nos demais espaços da Socieda$\mathrm{de}^{4}$, mas de explicitar a constituição do 'imaginário' que compõe a identidade cultural de um grupo e as condições para a convivência e interação com os demais.

Apresenta-se, de imediato, o problema desta pesquisa: o Estado é a única entidade a reconhecer quais culturas são legítimas para o aperfeiçoamento da Democracia, bem como o único espaço para a resolução de conflitos num cenário multicultural?

A hipótese formulada para essa indagação é, inicialmente, negativa, pois observa-se que a expressão multiculturalismo precisa ser compreendida na sua extensão global e expressar o compromisso moral com a ordem democrática e a construção de novos espaços capazes de fomentar a expressão das culturas e, quando necessário, a afirmação dos tradicionais. Atualmente, a democracia possui legitimidade na medida da sua capacidade de garantir a expressão das identidades culturais, equacionar as divergências e corrigir distorções.

Perseguindo essa meta, abordar-se-ão as implicações e demandas para o Direito, tanto para a sua estrutura legal quanto para as suas relações relativas à efetivação da justiça no cotidiano das relações culturais e nas manifestações públicas das diferenças.

A concepção de Direito e sua configuração diante da diversidade cultural indica a necessidade de esclarecer o que é Direito das Culturas e Pluralismo Jurídico, bem como identificar a pluralidade como o traço característico do mundo globalizado.

Essa é uma dinâmica de reflexão que desafia o direito para situar a sua abordagem com base na diversi-

4 "A sociedade, enquanto fenômeno humano, decorre da associação de homens, da vida em comum, fundada na mesma origem, nos mesmos usos, costumes, valores, cultura e história. Constitui-se sociedade no e pelo fluxo das necessidades e potencialidades da vida humana; o que implica tanto a experiência da solidariedade, do cuidado, quanto da oposição, da conflitividade. Organização e caos são polos complementares de um mesmo movimento - dialético - que dá dinamismo à vida da sociedade". DIAS, Maria da Graça dos Santos. Sociedade. In: BARRETO, Vicente de Paulo. Dicionário de filosofia política. São Leopoldo: UNISINOS, 2010. p. 9-553. p. 487. 
dade e exercer a tolerância ${ }^{5}$ com a introdução de outros valores, instituições e referências até então estranhas ou desconhecidas. A arquitetura que responde aos limites territoriais ou linguísticos, por exemplo, precisa ser criticada na sua fundamentação e nas consequências que podem gerar.

Com maior intensidade se pode perceber a insuficiência da apresentação formal da ordem jurídica. Considerando-se as novas relações que integram as relações sociais, afirmamos a necessidade de construir uma nova identidade jurídica acompanhada pela respectiva atualização da compreensão do valor da tolerância como o imperativo da democracia e para a complexa relação entre as culturas.

O Século XXI afirmará sua capacidade de construir Justiça na medida em que fomentar a efetivação do direito das culturas nos diversos contextos e a atualização dos valores mais importantes da democracia, especificamente a tolerância e os direitos humanos.

Por esse motivo, o objetivo geral deste estudo é determinar a importância do cenário multicultural na medida em que evidencia outros espaços de diálogos e resolução de conflitos além daqueles impostos pelo Estado. Com intuito de realizar essa finalidade, tem-se como objetivos específicos: a) reconhecer a importância dos cenários multiculturais a partir do fenômeno da Globalização; b) identificar que o Estado não é a única entidade capaz de resolver os conflitos humanos; c) averiguar quais culturas são legítimas para contri-

"A afirmação da Tolerância como um valor fundamental para a avaliação da arquitetura, do funcionamento, das garantias de estabilidade social e política, das políticas de desenvolvimento e das relações entre culturas ou concepções diferentes, inúmeras vezes conflitantes, representa a convicção moral e uma conquista histórica com condições de impulsionar os diferentes campos de relacionamento, organização e funcionamento das sociedades caracterizadas pelas deficiências e dificuldades para compreender e efetivar o exercício da práxis (sempre mais) tolerante. O valor da Tolerância precisa integrar o que se pode chamar de imaginário social ou, também, a compreensão de razão pública da sociedade democrática. Entretanto, a ausência de um exercício intrassubjetivo sobre o reconhecimento dos limites e deficiências humanas e sociais cria o self deception (autoengano) acerca do que é ser humano e, portanto, incita práticas sempre mais intolerantes". ZAMBAM, Neuro José; AQUINO, Sérgio Ricardo Fernandes de. Tolerância: reflexões filosóficas, políticas e jurídicas para o século XXI. Revista da AJURIS, Porto Alegre, v. 142, n. 137, p. 382, mar. 2015. Disponível em: <http://www.ajuris.org.br/OJS2/index.php/REVAJURIS/article/view/389/323>. Acesso em: 22 fev. 2016. buir ao aperfeiçoamento dos espaços democráticos e as diferentes legislações.

O Método de abordagem escolhido para conduzir a pesquisa apresentada neste artigo é o Indutivo ${ }^{6}$, cuja premissa menor é a existência, são os cenários multiculturais que se desdobram, no âmbito do Direito, com base no Pluralismo Jurídico - como premissa maior -, a sua adequação no cenário da Globalização e no Direito das Culturas. Na fase de Tratamento dos Dados, utiliza-se o Método Cartesiano ${ }^{7}$. As técnicas escolhidas com o intuito de viabilizar o Método são a Pesquisa Documental e Bibliográfica $^{8}$, a Categoria ${ }^{9}$, o Conceito Operacional ${ }^{10}$, bem como o Fichamento ${ }^{11}$.

\section{Globalização e culturas}

O impacto da globalização nas diferentes áreas do conhecimento, nas relações humanas e sociais na administração dos recursos naturais e ambientais, na produção e distribuição dos bens é visível, inegável e interfere rotineiramente com maior ou menor intensidade. O es-

6 " [...] base lógica da dinâmica da Pesquisa Científica que consiste em pesquisa e identificar as partes de um fenômeno e colecioná-las de modo a ter uma percepção ou conclusão geral". PASOLD, Cesar Luiz. Metodologia da pesquisa jurídica: teoria e prática. 12. ed. São Paulo: Conceito, 2011. p. 205.

7 "[...] base lógico-comportamental proposta por Descartes, [...], e que pode ser sintetizada em quatro regras: 1. duvidar; 2. Decompor; 3. ordenar; 4. classificar e revisar. Em seguida, realizar o Juízo de Valor”. PASOLD, Cesar Luiz. Metodologia da pesquisa jurídica: teoria e prática. 12. ed. São Paulo: Conceito, 2011. p. 204.

8 “...] Técnica de investigação em livros, repertórios jurisprudenciais e coletâneas legais". PASOLD, Cesar Luiz. Metodologia da pesquisa jurídica: teoria e prática. 12. ed. São Paulo: Conceito, 2011.p. 207.

9 “[...] palavra ou expressão estratégica à elaboração e/ou à expressão de uma idéia”. PASOLD, Cesar Luiz. Metodologia da pesquisa jurídica: teoria e prática. 12. ed. São Paulo: Conceito, 2011. p. 25. (Grifo do autor).

10 "Quando nós estabelecemos ou propomos uma definição para uma palavra ou expressão, com o desejo de que tal definição seja aceita para os efeitos das idéias que expomos, estamos findando um Conceito Operacional [...]" PASOLD, Cesar Luiz. Metodologia da pesquisa jurídica: teoria e prática. 12. ed. São Paulo: Conceito, 2011. p. 37. (Grifo do autor).

11 "[... Técnica que tem como principal utilidade otimizar a leitura na Pesquisa Científica, mediante a reunião de elementos selecionados pelo Pesquisador que registra e/ou resume e/ou reflete e/ou analisa de maneira sucinta, uma Obra, um Ensaio, uma Tese ou Dissertação, um Artigo ou uma Aula, segundo Referente previamente estabelecido". PASOLD, Cesar Luiz. Metodologia da pesquisa jurídica: teoria e prática. 12. ed. São Paulo: Conceito, 2011. p. 201-202. 
tudo do direito, as propostas de leis e as condições para a sua efetivação, assim como o preenchimento de vácuos jurídicos desafiam o tratamento das diversas questões de forma contextualizada, abrangente e isenta de fanatismos ou concepções isoladas ou reducionistas.

A atual conjuntura de relações e demandas existentes em diferentes campos do conhecimento e das demais áreas desafia a redefinição da identidade do estado como tutor das garantias jurídicas e responsável pelo funcionamento das sociedades, tradicionalmente limitadas pelo território que, simultaneamente, conferia a identidade individual e nacional dos seus membros.

Há inúmeras áreas que clamam respostas jurídicas que estão a descoberto devido, entre outras causas, à nova configuração das relações internacionais influenciadas pelo acelerado processo de globalização. Destacamos os conflitos relacionados às tecnologias da informação, especificamente aos crimes virtuais como o tráfico de pessoas ou de órgãos humanos, à troca ou ao comércio de produtos naturais e aos conflitos que envolvem as lutas pelo reconhecimento das culturas, à própria violência que tem como causa concepções culturais divergentes e a conflitos dessa mesma natureza que ultrapassam fronteiras territoriais ou às condições de controle e de atuação do Estado.

Esse relato indica, simbolicamente, as deficiências e os compromissos do direito em vista da sua atualização, recontextualização e capacidade de integrar outros atores e problemas que, até então, estavam restritos ao domínio das fronteiras nacionais. Afirmamos que não se pode restringir essa abordagem à reflexão e à formatação de propostas jurídicas limitadas ao território nacional ou ao alcance da autoridade política e judiciária local. Nesse contexto investigamos, especificamente, os temas que envolvam o Pluralismo Jurídico e o Direito das culturas (o multiculturalismo).

O Pluralismo Jurídico é mais que um conceito ou método de abordagem que implica a disposição e a capacidade para dialogar além das convicções individuais, da tradição cultural, da tradição política e da concepção individual de justiça. Sem essa dinâmica, a reflexão crítico-pedagógica, o exercício profissional se tornam insuficientes, limitados e insossos ${ }^{12}$.

12 "O direito não é mais uma coisa do Estado, mas também parece deixar de ser expressão da vontade de um povo, como cria o melhor da tradição democrática. [...] Assim, lidar com o direito hoje, descrevê-lo, ensinar a trabalhar
A relevância dessa abordagem demonstra parte das dificuldades de efetivação da justiça nas sociedades contemporâneas caracterizadas pela complexidade. Essa dinâmica cultural compromete tanto a formação individual quanto as instituições, especificamente o sistema jurídico. Destacamos:

o multiculturalismo representa essa ampla rede de relacionamentos que as pessoas estabelecem entre si e com uma variedade de situações que contribuem, decisivamente, para a formação da sua identidade individual e social, a partir da qual podem influenciar o ambiente onde vivem e os demais campos de sua atuação. A atenção ao multiculturalismo é condição indispensável para a avaliação das questões de justiça nas sociedades contemporâneas. É necessário, primeiramente, o reconhecimento da importância da formação cultural das pessoas e suas implicações nos diferentes espaços onde elas convivem e ao qual podem influenciar ${ }^{13}$.

As relações entre as culturas, especificamente, nos ambientes caracterizados pela pluralidade de tradições, valores, hábitos e concepções precisam superar a lógica da dominação, imposição, classificação ou avaliação orientadas pela busca do sucesso econômico, da integração das minorias, da aniquilação das divergências ou mesmo da disputa entre as mais influentes ou melhor organizadas.

A busca pelo reconhecimento dos direitos das culturas precisa ser pautada pela tolerância, porque, sabendo da sua destacada importância moral, tem condições para orientar, educar e sancionar soluções que visem congregar e equalizar problemas ou divergências no interior de sociedades formadas pela diversidade de culturas e concepções.

A tolerância é o princípio consagrado pela tradição democrática com as condições de orientar e sancionar as principais soluções de conflitos entre pessoas

com ele, fazer a sua teoria, implica tomá-lo como de fato ele é nos nossos dias. E, consequentemente, ter sempre presente que o direito é um fenômeno mutável nas suas fronteiras, plural nas suas fontes de criação e revelação, complexo na sua lógica interna, não consistente nem harmônico nos seus conteúdos, e, finalmente, nada afeito a um saber que retenda certezas e formulações seguras e não opináveis. Em suma, trabalhar com o direito exige que se assuma que ele é algo de 'local', de plural, de equívoco, sujeito às controvérsias ('opinável', 'argumentável') e ao convívio e a disputa de outras ordens normativas". HESPANHA, Antônio Manuel. Pluralismo jurídico e direito democrático. São Paulo: Annablume, 2013, p. 19.

13 ZAMBAM, Neuro José. Amartya Sen: liberdade, justiça e desenvolvimento sustentável. Passo Fundo: IMED, 2012. p. 255 . 
e grupos. As principais demandas por reconhecimento cultural advêm das incontáveis referências que compõem a formação individual e, por consequência, a identidade coletiva das pessoas, grupos e sociedades. Nesse contexto, esclarece Taylor: "Por isso, o respeito devido não é um ato de gentileza para com os outros. È uma necessidade humana vital ${ }^{14 "}$.

As culturas, quanto mais integradas, publicizadas e reconhecidas, melhor evidenciam a sua importância, seu potencial e seus limites ${ }^{15}$. Com a mesma intensidade, geram apreensão, desconfiança e ameaça às culturas que escondem ou encerram sua identidade em círculos fechados, seja do ponto de vista das relações pessoas, seja da sua geografia. A educação para a tolerância, nesse contexto, tem como meta a sua introdução na concepção moral, no funcionamento das instituições e na arquitetura jurídica.

O pluralismo jurídico e cultural nas sociedades democráticas interessa, sobremaneira, ao direito, visto que é o direito o responsável pelo ordenamento das diferenças e a respectiva sanção das ameaças e dos eventuais delitos. A tolerância precisa perpassar a rotina da convivência social e jurídica. A legislação consagra a garantia dos direitos, a sua efetivação de forma equitativa e os mecanismos de decisão. Especificamente o critério da maioria tem como contraponto o respeito e a integração das minorias.

A unanimidade e a imposição da vontade única são ameaças quando, publicamente ou sorrateiramente, atuam com a mesma intensidade que a ausência do exercício da autoridade política ou da ordem legal.

Os desafios do pluralismo cultural e jurídico das sociedades contemporâneas demandam o exercício da liberdade, o esclarecimento público e a ampliação progressiva das formas de participação. O imaginário público e simbólico acompanhado da percepção da legitimidade moral e jurídica do direito à expressão cultural sedimentam relações o equilíbrio social e o ambiente para a justiça social. A identidade social será de tolerância, pluralidade e democracia. O desenvolvimento de estratégias e mecanismos para a sua efetivação permitirá o equilíbrio do futuro.

14 TAYLOR, Charles. Multiculturalismo. Lisboa: Instituto Piaget, 1994. p. 46.

15 "[...] cada uma das nossas vozes tem algo de único a nos dizer”. TAYLOR, Charles. Multiculturalismo. Lisboa: Instituto Piaget, 1994. p. 51.

\section{Globalização e pluralismo jurídico}

Desde que o ser humano olhou para o horizonte e se lançou a explorar terras e mares, a fim de descobrir outros locais, outras culturas, evidencia-se o (intenso) aperfeiçoamento de mundo globalizado ${ }^{16}$. O Direito ${ }^{17}$, sob semelhante argumento, sofre as suas metamorfoses devido a essas interações globais, seja na Economia, na Política, na Tecnologia, nos diálogos culturais, entre outros cenários. A experiência jurídica não se exaure nos limites territoriais nacionais ou internacionais, mas revela-se transnacional na vida local cotidiana. É com base nessa epifania hologramática ${ }^{18}$ entre diferen-

16 "[...] A história do Ocidente Mediterrâneo e da Cristandade Medieval caracteriza-se por tentativas imperialistas com ambições 'mundiais'. O mundo romano, os Papas, a Idade-Média, os Estados nascentes, Portugal, Espanha, França, Inglaterra e Alemanha, tiveram todos, na sua época, tais pretensões. No entanto, esses esforços sucessivos de dominação estavam muito distantes do que se entende hoje por 'globalização' [...]. O que ocorreu, com esse processo chamado de 'globalização' não por um modismo, mas para expressar uma especificidade, foi uma ruptura brutal e radical com o modo de pensar e agir ligado à 'modernidade' [...]. A progressiva unificação do mundo, a formação da chamada aldeia global, foi um processo percebido com nitidez crescente neste ciclo [...]. A globalização implica, portanto, uma reorganização espacial da vida social: os espaços tradicionalmente reservados ao direito e à política não coincidem mais com o espaço territorial. ARNAUD, André-Jean; JUNQUEIRA, Eliane Botelho. Dicionário da globalização. Rio de Janeiro: Lúmen Juris, 2006. p. 222-223.

17 "[...] O fenômeno da globalização, ao mesmo tempo que possibilita o intercâmbio e influências recíprocas entre as comunidades internacionais - processo que permite uma uniformização da cultura - também ressalta e divulga as particularidades das comunidades locais. Por necessidade de identificação dessas comunidades, esse movimento de globalização, que é expansionista e delimitador do particular, permite que fale, hodiernamente, num pluralismo contemporâneo. [...] Dessa forma, é possível trabalhar com internormatividade, que se caracteriza por várias fontes de produção do Direito, algumas delas reconhecidas pelo Estado, outras, não. Embora revelem maior eficácia na resolução dos problemas, essas inovações permitem que se pense numa socialização do Direito". DALANEZE, Sérgio. Contribuição do pluralismo no debate das ideias jurídicas. In: WOLKMER, Antônio Carlos; VERAS NETO, Francisco Q. ; LIXA, Ivone M. (Orgs.). Pluralismo jurídico: os novos caminhos da contemporaneidade. São Paulo: Saraiva, 2010, p. 7-342. p. 75

18 "Um holograma é uma imagem que cada ponto contém a quase totalidade da informação sobre o objeto representado. O princípio hologramático significa não apenas que a parte está no todo, mas que o todo está inscrito, de certa maneira, na parte. Assim, a célula contém a totalidade da informação genética, o que permite, em princípio, a clonagem. A sociedade, como todo, pela cultura, está presente no espírito de cada indivíduo". MORIN, Edgar. O método 6: ética. Porto Alegre: Sulina, 2005, p. 207. 
tes culturas que se torna possível estudar o Pluralismo Jurídico ${ }^{19}$.

$\mathrm{Na}$ medida em que o tempo apresenta desafios mais complexos e plurais, observa-se como o Direito ${ }^{20}$ não se torna eficaz pelo discurso universalizante proposto pelo Estado. As indagações direcionadas para essa categoria - Direito - já sinalizam que a função centralizadora estatal não corresponde à resolução de conflitos, sejam culturais, tecnológicos, ambientais ou econômicos.

O Direito não é um fenômeno que existe por si, que se esgota nos seus próprios significados e tampouco cuja autonomia seja determinada exclusivamente pelas leis, pelas doutrinas ou pela jurisprudência. As suas fontes são plurais e reivindicam igual apreciação pelas suas diferentes contribuições à manutenção da organização (e unidade) social ${ }^{21}$. A natureza do Direito não é originária da uníssona voz estatal, mas dos ecos das relações humanas produzidas nas galerias subterrâneas do nosso dia a dia.

A tarefa de propor convívio local22 - no seu senti-

19 "[...] este pluralismo jurídico a que nos referimos, antes de ser algo que surgiu nos nossos dias, por circunstâncias particulares dos tempos e das políticas, é antes algo de sempre, pois tem a ver com a maneira de ser dos próprios grupos humanos - a sua diversidade de maneiras de ver o mundo, as relações dele com os homens e as que os homens mantém entre si. Ibi societas, ibi iura (agora no plural)". HESPANHA, Antônio Manuel. Pluralismo jurídico e direito democrático. São Paulo: Annablume, 2013. p. 13.

20 Categoria multidisciplinar que se revela como "[...] compreensão [...] in acto, como efetividade de participação e de comportamentos, sendo, essencial ao seu conceito a vivência atual do direito, a concreta correspondência das formas da juridicidade ao sentir e querer, ou às valorações da comunidade". REALE, Miguel. O direito como experiência: introdução à epistemologia jurídica. 4. tir. São Paulo: Saraiva, 2010, p. 31. (Grifo do autor)

21 "... [ realizar o direito da comunidade por sobre os direitos dos grupos pressupõe consensos quanto às regras de conviver. Consensos, porém, há muitos. Evitando qualificativos que dependam das valorações de cada um - como consensos jutos e consensos injustos - fiquemo-nos em que há consensos mais sustentáveis do que outros". HESPANHA, Antônio Manuel. Pluralismo jurídico e direito democrático. São Paulo: Annablume, 2013. p. 14.

22 "Do ponto de vista do 'localismo', o poder local é o nível mais descentralizado do poder estatal, organizado e articulado por relações que mais diretamente são atravessadas pela sociedade e pelos interesses advindos das forças sociais. O 'localismo', como uma das instituições chave da democracia pluralista, procura favorecer condições estratégicas que permitam a produção direta e a movimentação de bens e serviços, acentuando processos decisórios alicerçados em técnicas de ação comunitária e participativa, bem como reforçando regionalmente a implementação deliberatória e executiva das ações coletivas e de suas funções no do silencioso e microscópico - a partir de diferentes diálogos culturais não é algo fácil. Vive-se, diariamente, em cada cidade, valores os quais não representam uma identidade daquele espaço humano, mas vetores não territoriais - transnacionais - que estimulam - para mais ou para menos - as condições de paz $^{23}$ entre as pessoas. Por esse motivo e segundo essas "interferências globais”, o Direito não é mais um produto exclusivo do Estado e, também, não representa a vontade do povo ${ }^{24}$.

$\mathrm{O}$ primeiro argumento indica a necessidade de se observar quais são os espaços que produzem o Direito. Os conselhos de bairros, as associações, as Organizações Não Governamentais (ONG’s), as escolas, as universidades, os locais de trabalho, os templos religiosos, todos esses lugares são capazes de expressar seus interesses na busca de uma vida mais democrática e qualitativa. O Estado, ao elaborar um discurso homogêneo e universal por meio das leis, despreza todas as formas de diálogo que ali não estejam inseridas. O estrangeiro, o "esquecido", o "cidadão descalço", não representam os interesses estatais e nem da vontade geral do povo.

Não existe, sob igual critério, uma única vontade do povo, mas voláteis interesses de gêneros, de religiões, de culturas, de classes, de poderes instituintes e instituídos. Percebe-se o conflito de necessidades individuais e coletivas entre as pessoas todos os dias. Partilhar os mesmos espaços geográficos com diferentes fontes de compreensão do mundo requer contínuos modos de se vivenciar a experiência da diferença. Essa participação, esse "estar junto com o Outro" amplia e renova os consensos democráticos, bem como enfatiza a necessidade de se encontrar a estabilidade e harmonia entre as diferentes fontes dos direitos ${ }^{25}$.

âmbito da família, vizinhança, igreja, comitês de bairro, associação local e comunidade restrita". WOLKMER, Antonio Carlos. Pluralismo jurídico: fundamentos de uma nova cultura no Direito. 3. ed. São Paulo: Alfa-Omega, 2001, p. 176.

23 "A Paz, enquanto manifestação da cultura humana, procura orientação naquilo que traga identificações de CONVIVÊNCIA, de vida, de reconhecimento do Outro pelo seu vínculo antropológico comum". AQUINO, Sérgio Ricardo Fernandes de. O direito em busca de sua humanidade: diálogos errantes. Curitiba: CRV, 2014, p. 55.

24 HESPANHA, Antônio Manuel. Pluralismo jurídico e direito democrático. São Paulo: Annablume, 2013. p. 19.

25 "[...] consensos formados a partir de um diálogo alargado, participado e que reflita sobre a complexidade das coisas, têm muito mais condições para serem duráveis, embora não definitivos". HESPANHA, Antônio Manuel. Pluralismo jurídico e direito democrático. São Paulo: Annablume, 
A defesa de um Pluralismo Jurídico, nesse cenário globalizado, deve indicar “[...] a multiplicidade de práticas jurídicas existentes num mesmo espaço sociopolítico, interagidas por conflitos ou consensos, podendo ser ou não oficiais e tendo a sua razão de ser nas necessidades existenciais, materiais e culturais ${ }^{26 "}$. O Direito somente se torna unidade de sentido, projeto civilizacional para todos, quando observado e vivenciado pela pluralida$\mathbf{d e}^{27}$ de cenários, de falas, de locais nesse theatrum mundi.

A América do Sul já compreendeu a importância dessa dimensão plural pelos seus diferentes povos. Países como a Bolívia estabeleceu, em sua constituição, a ideia da "plurinacionalidade"28. Sob igual argumento, o Tratado Constitutivo da União de Nações Sul-Americanas UNASUL - demanda uma integração participativa com base nas diferenças ${ }^{29}$ que habitam e unem as pessoas no

\section{3. p. 14.}

26 WOLKMER, Antonio Carlos. Pluralismo jurídico: fundamentos de uma nova cultura no Direito. 3. ed. São Paulo: Alfa-Omega, 2001. p. 219. (Grifo do autor)

27 "A justiça é uma invenção humana e duvida-se que seja feita de uma só maneira. [...] As questões apresentadas pela teoria da justiça distributiva admitem uma série de respostas, e há espaço dentro dessa série para a diversidade cultural e as opções políticas. Não é só questão de implementar algum princípio singular ou conjunto único de princípios em diversas circunstâncias históricas. Ninguém negaria que existe uma série de implementações moralmente permissíveis. Quero defender mais do que isso: que os princípios de justiça são pluralistas na forma; que os diversos bens sociais devem ser distribuídos por motivos, segundo normas e por agentes diversos; e que toda essa diversidade provém das interpretações variadas dos próprios bens sociais - o inevitável produto do particularismo histórico e cultural". WALZER, Michael. Esferas da justiça: uma defesa do pluralismo e da igualdade. São Paulo: Martins Fontes, 2003, p. 4-5.

28 Artículo 1 Bolivia se constituye en un Estado Unitario Social de Derecho Plurinacional Comunitario, libre, autonómico y descentralizado, independiente, soberano, democrático e intercultural. Se funda en la pluralidad y el pluralismo político, económico, jurídico, cultural y lingüístico, dentro del proceso integrador del país. El Estado Unitario Social de Derecho Plurinacional Comunitario tiene como máximo valor al ser humano, y asegura el desarrollo equitativo mediante la redistribución de los excedentes económicos en políticas sociales, de salud, educación y cultura. TRANSPARÊNCIA LEGISLATIVA. Constituición del Bolívia. 2013. Disponível em: <http://www.transparencialegislativa.org/wpcontent/uploads/2013/04/Constitucio\%CC\%81n-Bolivia.pdf.>. Acesso em: 2 abr. 2015.

29 A leitura do Preâmbulo deste Tratado demonstra: "[...] RATIFICANDO que tanto a integração quanto a união sul-americanas fundam-se nos princípios basilares de: irrestrito respeito à soberania, integridade e inviolabilidade territorial dos Estados; autodeterminação dos povos; solidariedade; cooperação; paz; democracia, participação cidadã e pluralismo; direitos humanos universais, indivisíveis e in- continente sul-americano. Reivindica-se uma cidadania plural $^{30}$ capaz de tornar possível conhecer e vivenciar as agonias, as dificuldades, as esperanças e a cumplicidade de cada vida local.

Os desafios do Pluralismo Jurídico ${ }^{31}$, como apresentados nos dois exemplos anteriores, não são fenômenos cujos significados, funções e resultados ocorram de modo imediato, entretanto, sinalizam duas preocupações neste mundo de relações globais vividos em locais que batalham para não perderem suas características históricas e culturais, quais sejam: a) o estímulo para se consolidar critérios de tolerância por meio de uma ética da alteridade e; b) identificar quais são as responsabilidades compartilhadas na medida em que as ações desmedidas importam em uma má qualidade de vida para as pessoas.

A vivência entre culturas diferentes denota um esforço para que haja múltiplas convergências com o objetivo de reforçar e ampliar a importância - especialmente dialogal - dos espaços democráticos. Essa experiência aumenta nossas capacidades sensíveis ${ }^{32}$ para as dificulda-

terdependentes; redução das assimetrias e harmonia com a natureza para um desenvolvimento sustentável;". BRASIL. Decreto n. 7.667, de 11 de janeiro de 2012. Brasília, 2012. Disponível em: <http://www.planalto.gov.br/ccivil_03/_ Ato2011-2014/2012/Decreto/D7667.htm>. Acesso em: 2 abr. 2015. (Grifo do autor).

30 "Artigo 18 - Participação Cidadã: Será promovida a participação plena da cidadania no processo de integração e união sul-americanas, por meio do diálogo e da interação ampla, democrática, transparente, pluralista, diversa e independente com os diversos atores sociais, estabelecendo canais efetivos de informação, consulta e seguimento nas diferentes instâncias da UNASUL. Os Estados Membros e os órgãos da UNASUL gerarão mecanismos e espaços inovadores que incentivem a discussão dos diferentes temas, garantindo que as propostas que tenham sido apresentadas pela cidadania recebam adequada consideração e resposta". BRASIL. Decreto n. 7.667, de 11 de janeiro de 2012. Brasília, 2012. Disponível em: <http://www.planalto.gov. br/ccivil_03/_Ato2011-2014/2012/Decreto/D7667.htm>. Acesso em: 2 abr. 2015. (Grifo do autor).

31 "[... Trata-se de um lento processo de experimentação, erro e correção. No qual nem é certo que os juristas desempenhem um papel de protagonistas, porque, [...], muito dos saberes usuais dos juristas poderão constituir antes obstáculos do que instrumentos úteis. Sobretudo porque aquilo que eles têm por assente e que, frequentemente, resistem a repensar, faz parte de um saber datado, com mais de dois séculos de idade, referido a um modelo de poder que não é o de hoje". HESPANHA, Antônio Manuel. Pluralismo jurídico e direito democrático. São Paulo: Annablume, 2013. p. 15.

32 Rifkin enfatiza: Lo irónico es que cuando una cultura basada en la vengüenza intenta alcanzar los niveles más elevados de perfección moral, acaba creando una cultura de envidia, celos y odio hacia uno mismo y hacia los demás. A 
des locais e conduz a procura de medidas racionais para diminuir as misérias humanas.

Entretanto, essa condição somente se torna possível quando se fomenta uma "Ética da Alteridade"33. A Alteridade se torna esse critério ético primeiro porque esclarece a importância da diferença que habita o Outro para a constituição plural de nossa personalidade. As relações humanas fundamentadas pela Alteridade estimulam essa responsabilidade incondicional pela presença desse "estrangeiro" em nossas vidas e oportunizam a habitualidade de ações tolerantes ${ }^{34}$ e solidárias.

$\mathrm{Na}$ dimensão ética, como se enfatizou, há necessidade de se compartilhar responsabilidades. No entanto, é sempre difícil determinar "responsabilidade de quem?". Percebe-se como o "sujeito individualista" descreve - de modo negativo - a responsabilidade como punição e não

lo largo de la historia, las culturas basadas en la vengüenza han sido las más agresivas y violentas, porque sufocan el impulso empático y, con él, la capacidad de sentir el sufrimiento de los demás y de responder a él con compasión. RIFKIN, Jeremy. La civilización empática: la carrera hacia una conciencia global en un mundo en crisis. Barcelona: Paidós, 2010, p. 122.

33 "[... A 'ética da alteridade' não se prende a engenharias 'ontológicas' e a juízos a priori universais, postos para serem aplicados a situações vividas, mas traduz concepções valorativas que emergem das próprias lutas, conflitos, interesses e necessidade de sujeitos individuais e coletivos insurgentes em permanente afirmação. Admite-se, assim, que a 'ética concreta da alteridade' tem um cunho libertário, pois, por estar inserida nas práticas sociais e delas ser produto, pode perfeitamente se materializar como instrumento pedagógico que melhor se adapta aos intentos de conscientização e transformação das lutas de libertação e emancipação nacional dos povos oprimidos". WOLKMER, Antonio Carlos. Pluralismo jurídico: fundamentos de uma nova cultura no direito. 3. ed. São Paulo: Alfa-Omega, 2001. p. 268.

34 "Cabe, por fim, estender ao pluralismo a noção moderna do princípio da 'tolerância'. Ora, na medida em que a natureza humana é motivada por necessidades concorrentes, por disposições de vidas marcadas por conflitos de interesses e pela diversidade cultural e religiosa de agrupamentos comunitários, o pluralismo resguarda-se através de regras de convivência pautadas pelo espírito de indulgência e pela prática da moderação. A filosofia da tolerância não só está associada à filosofia da liberdade humana, mas, igualmente, ao direito de autodeterminação que cada individuo classe ou movimento coletivo possui de ter sua identidade própria e ser diferente funcionalmente dos outros. A 'tolerância' que implica o bom-senso e a pré-disposição de aceitar uma vida social materializada pela diversidade de crenças e pelo dissenso de manifestações coletivas vem a se constituir, [...], a suprema virtude do pluralismo democrático". WOLKMER, Antonio Carlos. Pluralismo jurídico: fundamentos de uma nova cultura no direito. 3. ed. São Paulo: Alfa-Omega, 2001. p. 177. desvelo para um atuar conjunto, tampouco nossas incapacidades momentâneas no intuito de contribuir para essa finalidade. Partilhar responsabilidades por ações não produzidas é um desafio para o século XXI, afinal, a advertência de Santos é clara: toda responsabilidade é corresponsabilidade ${ }^{35}$.

A "Ética da Alteridade" formula três indagações as quais permitem reconhecer os limites de contribuição para a amplitude de ações mais responsáveis, ou seja, identifica-se o surgimento da responsabilidade e em que medidas todos podem contribuir para o seu aperfeiçoamento. Não se observa, nesse caso, a indiferença patológica que causa a inércia solidária por argumentos que demonstrem a ausência de sujeitos que provocaram uma ação e seu dano. As perguntas se referem à natureza da responsabilidade (Qual é a responsabilidade?), a sua origem (Por que ser responsável?) e seu destinatário (Para quem é a responsabilidade ou os seus efeitos?).

O "estar junto" histórico e cultural do continente sul-americano evidencia, ainda que de modo microscópico, como a Alteridade não apenas esclarece a sua importância como critério ético, mas, também, fomenta o vínculo humano pela participação no reconhecimento do Outro como ser livre que contribui - direta ou indiretamente - para assegurar condições de práticas sociais as quais não sejam delimitadas tão somente pelas regras estatais, porém, especialmente, demandem - de nacionais ou estrangeiros - como é possível elaborar um conhecimento no qual seja capaz de incentivar a elaboração de espaços, de critérios, de formas, de conteúdos os quais esclareçam o nosso destino de humanidade na vida cotidiana.

A proximidade entre diferentes culturas descritas como fonte de convivialidade resgata o prazer pela experiência da vida. Nos diálogos, nos desafios, nas dificuldades, nas vitórias, há algo que estimula a compreensão da Alteridade. As diferentes - e desconhecidas - vias do dia a dia local permitem identificar e experimentar situações cujo desenho forma uma bela imagem artística. Essas sensações são favorecidas, também, pelas comunicações globais as quais permitem conhecer novos horizontes carregados de esperança ${ }^{36}$. Novamente, a cumplicidade

35 SANTOS, Boaventura de Sousa. A crítica da razão indolente: contra o desperdício da experiência. 5. ed. São Paulo: Cortez, 2005. v. 1. p. 113.

36 "Enquanto houver fundadas esperanças por parte capazes de influenciar, decidir, ensinar e exemplificar, poder-se-á aguardar que não só seja possível construir o futuro desejá- 
do "estar junto" desvela os significados de um conhecimento pautado pela Liberdade, Igualdade e Fraternidade.

O Pluralismo Jurídico não se refere ao conhecimento de um Direito dissociado das mazelas e virtudes de uma vida global experimentada em diferentes localidades. Ao contrário, pela pluralidade se reconhece as manifestações de Alteridade, a fim de estimular, evidenciar, compreender e exercitar ações responsáveis (sentido ético ${ }^{37}$ ) por pessoas as quais desejam participar de uma experiência fora dos domínios de seus saberes habituais, a fim de assegurar a importância dos cenários livres e democráticos fora dos limites impostos pelo Estado nacional (sentido político). Por esse motivo, o prazer da convivência, dos diferentes convites feitos por pessoas, pela arquitetura dos locais ou os segredos culturais demanda que o ser esteticizado não se conforme, se indigne, com todas as formas de opressão ou que dificultem o reconhecimento mínimo dessa aventura transfronteiriça chamada dignidade (sentido estético).

A ideia de Justiça, com base no Pluralismo Jurídico, reivindica outro senso comum cujos horizontes sejam éticos, políticos e estéticos. É a partir desses diferentes locais, com diferentes sensações e diferentes oportunidades de se estabelecer diálogos e participações na vida local que se constituem mecanismos mais amplos para

vel, como haverá estímulo para disseminar aquelas mesmas esperanças através do cultivos das utopias que descortinem um mundo menos opressor, com fundamentos científicos e religiosos que substituam a arrogância das certezas pela busca incessante da verdade e da felicidade, com o coração e a mente abertos a novas descobertas. Assim, talvez conscientemente percebamos aí o desenho das trilhas a percorrer para adentrarmos com um mínimo de segurança na pós-modernidade". MELO, Osvaldo Ferreira de. O papel da política jurídica na construção normativa da pós-modernidade. In: DIAS, Maria da Graça dos Santos; MELO, Osvaldo Ferreira de; SILVA, Moacyr Motta da (Org.). Política jurídica e pós-modernidade. Florianópolis: Conceito, 2009. p. 9-236. p. 94.

37 "[...] Precisamente por isso, a convivência humana coloca em questão a ética, porque não se trata de convivência entre iguais, mas de diferentes. Esta marca é constitutiva das relações sociais, que nunca se reduzem a simples justaposição de indivíduos, mas a uma unidade de contrários, polarizada. As relações sociais são compostas de dinâmicas ambivalentes, de atração e repulsão, dialéticas, permeadas por trama de poder e influência na qual somos ora mais objetos, mais sujeitos. Em sociedade, não existe presença estática, neutra. Estar juntos significa naturalmente participar de trama conjunta de influencias mútuas. Não é viável fazer seu destino sozinho. Ao contrário, todo destino individual é tecido na trama social". DEMO, Pedro. Éticas multiculturais: sobre a convivência humana possível. Petrópolis, RJ: Vozes, 2005, p. 20. se reconhecer as possíveis opções, as possíveis respostas aos principais dilemas humanos e que estão escondidas, invisíveis, para um Direito incapaz de enxergar na pluralidade a via para o cumprimento de sua função social.

\section{Direito das culturas e justiça}

A necessidade de construir relações de justiça nas sociedades marcadas pelo pluralismo foi assinalada e justificada por Rawls em sua vasta obra. As divisões de ordem filosófica, religiosa e moral são representativas, especificamente, das diferenças, divergência, incompreensões e fanatismos existentes em nível global.

O Direito dos Povos, obra que se pode chamar de uma utopia para o direito internacional, está sublinhado nessa necessidade de justiça entre os diferentes, sem negar, excluir ou classificar o outro em graus de importância, dignidade ou poder de influência ${ }^{38}$ :

o respeito mútuo implica, por sua vez, a vontade e capacidade generalizadas de conciliar os nossos desentendimentos, de defendê-los perante aqueles de quem discordamos, de discernirmos entre divergência respeitável e desrespeitável, e de nos abrirmos e sermos receptivos à mudança quando precedida de crítica bem fundamentada. A garantia moral do multiculturalismo depende da prática destes méritos de deliberação ${ }^{39}$.

O desafio para se criar condições de Justiça num ambiente multicultural ultrapassa o sentido de cooperação internacional ${ }^{40}$, mas ratifica-se pelo reconhecimento e contribuição de medidas de responsabilidade que todos têm e como é possível identificar e participar para a mitigação das misérias humanas sem que se apele para a (indiferente) expressão universal: toda a humanidade.

As interações entre múltiplas culturas, no tempo e espaço, denotam o esforço histórico para se constituir um direito dos povos. Entretanto, o caráter universal de determinadas expressões como toda a humanidade ou digni-

38 "Um direito dos povos (razoável) deve ser aceitável para povos razoáveis que são assim diversos, deve ser imparcial entre eles e eficaz na formação dos esquemas maiores de cooperação. RAWLS, John. O direito dos povos. São Paulo: Martins Fontes, 2001, p. 16.

39 TAYLOR, Charles. Multiculturalismo. Lisboa: Instituto Piaget, 1994. p. 43

40 "[...] 'Internacional' (com o prefixo 'inter' e a radical 'nação') supõe a existência de relações necessárias entre as nações - ideia que precisamente a globalização desafia. 'Internacional' não é 'global'". ARNAUD, André-Jean. $O$ direito entre modernidade e a globalização: lições de filosofia do direito e do estado. Rio de Janeiro: Renovar, 1999. p. 7. 
dade responde tão somente uma pergunta: o que fazer? Outra indagação surge imediatamente, porém sem resposta: como fazer? O nível de abstração de ambos questionamentos não localiza, na vida cotidiana, os elementos próprios para que se identifiquem as responsabilidades e os modos de deliberação plurais para uma convivência sadia desse vínculo antropológico comum.

Quando se percebem ações estatais as quais interferem - silenciosamente - nos modos de desenvolvimento civilizatório de outras culturas, diminuindo-lhes condições ou capacidades para estabelecer mecanismos administrativos, políticos, econômicos, tecnológicos e judiciais, a fim de assegurarem cenários mais pacíficos, sabe-se que todos - pela ação ou omissão - contribuíram para aquele resultado.

No entanto, é necessário identificar quem causa - em maior ou menor escala - essas situações para determinar quais medidas o responsável deverá cumprir para mitigar as fatalidades que suprimiram oportunidades de desenvolvimento nacional e transfronteiriço. Esse é o perigo de uma abstração genérica descrita como uma responsabilidade solidária: ninguém se sentiria responsável para apresentar ações com o objetivo de amenizar os conflitos, as desigualdades, as mortes decorrentes da vontade de alguém.

Por esse motivo, o raciocínio indutivo utilizado para encontrar respostas num cenário multicultural saberá: a) sinalizar que tipos de ações empreendidas por algumas nações conduzem à redução de direitos, de desenvolvimento, de qualidade de vida em detrimento à sua melhoria e manutenção e; b) ampliar a responsabilidade ao indicar de que maneira todos contribuem para amenizar as mazelas de um território nacional, conforme suas condições e necessidades. Essas condutas possibilitam, minimamente, decidir de que modo a pluralidade cultural demanda por responsabilidade local e não indiferença global. Nessa linha de pensamento, a advertência de Ricoeur ${ }^{41}$ é sensata: “[...] Fatalidade é ninguém; responsabilidade é alguém".

A elaboração da Justiça ${ }^{42}$ - e a sua necessidade

${ }^{41}$ RICOEUR, Paul. O justo 1: a justiça como regra moral e como instituição. São Paulo: Martins Fontes, 2008, p. 51.

42 Cunha, sob essa condição, rememora: "Da mesma forma que, quando somos injustamente esbofeteados, clamamos por justiça, e podemos fazer um belo discurso, também serve para provar que a Justiça não é uma abstração. E, como já vira Aristóteles, um dos primeiros grandes teóricos sistemáticos da Justiça, pela negação é que se vai à histórica - por meio do Multiculturalismo e Pluralismo Jurídico ${ }^{43}$ se evidencia pelo seu contrário: a Injustiça. As diversas formas de privações, a ausência de responsabilidades, o desrespeito contra o Outro se manifestam de modo endêmico em todo o território terrestre. Todos os dois fenômenos apresentados neste estudo demandam por proximidade, por participação, por reconhecimento às dificuldades experimentadas pela colisão - e possível, aproximação - entre mundos tão complexos e diferentes.

Os diferentes sujeitos - estatais e não estatais - que expressam as suas vontades estão sob a égide do Direito, seja na sua acepção cultural ou normativa. Na primeira dimensão, observa-se como a relação multicultural preserva as suas diferenças, mas reconhece-se o Outro como alguém necessário para a formação de nossas identidades e personalidades. A sugestão de Sennet acerca do respeito parece adequada para se compreender o Direito nessa definição de cultura.

Existem diferentes talentos no mundo. Os vários matizes culturais entoam a sua beleza como uma obra de arte. No entanto, o talento encoberto sobre a sua importância pouco contribui ao reconhecimento, à honra, à paz. A participação de uma pluralidade de sujeitos desvenda o sentido da cooperação, da responsabilidade. Os talentos precisam ser negociados, precisam convergir para gerarem a boa convivência, seja no espaço local ou global. É este o ponto de mutualidade entre todos: o respeito. Esta é a condição que fomenta o reconhecimento e, pela advertência de Sennet, evita aquele abismo entre esperar agir bem em relação aos outros e agir bem de fato ${ }^{44}$.

Sob outro ângulo, o Direito, no seu sentido normativo, expressa a vontade comunitária ${ }^{45}$ nos seus dife-

afirmação, pela justiça é que se chega à justiça". CUNHA, Paulo Ferreira da. Breve tratado da (in)justiça. São Paulo: Quartier Latin, 2009. p. 52.

43 Vale, nesse momento, a crítica de Cunha: "Perante a complexidade, a tendência acaba muito por ser o agarrar-se às leis. Tudo isto modera muito as miragens (generosas as mais das vezes, mas por vezes irrealistas) e muito reitera o positivismo (quase sempre nada generoso). Mas é, convenhamos, também algo empobrecedor". CUNHA, Paulo Ferreira da. Breve tratado da (in)justiça. São Paulo: Quartier Latin, 2009. p. 95.

44 SENNET, Richard. Respeito: a formação do caráter num mundo desigual. Rio de Janeiro: Record, 2004. p. 77-78.

45 "[...] o direito é aquilo que a comunidade reconhece como tal, não apenas por resultados dos processos de manifestação da vontade comunitária próprios do Estado democrático, mas também pode ser reconhecido como tal por instâncias jurisdicionais de um consenso comunitário inclusivo, reflexivo e estabilizador". HESPANHA, Antônio Manuel. 
rentes locais de manifestação, reconhecido, tanto pelo Legislativo quanto pelo Judiciário, pela validade e vigência da norma jurídica. A primeira ressalta uma qualidade que reúne preocupação com o conteúdo originário dessa pluralidade cultural tida como indispensável à convivência (validade material) reconhecida pelos poderes estatais instituídos, especialmente quanto à observância dos procedimentos à criação legislativa (validade formal).

A segunda - vigência - destaca um critério temporal. A expressão normativa tem significado no tempo enquanto trouxer, no seu conteúdo, por um lado, condições de viabilidade para se exercer, de modo pacífico, uma democracia multicultural e, por outro, reivindicar as suas promessas sempre quando forem omitidas ou suprimidas da vida cotidiana.

De modo resumido, pode-se afirmar que a vigência se refere à contínua atualidade dos desejos entre as diferentes culturas (locais ou globais). A validade representa o modelo de legitimação daquilo que se torna necessário para ampliar e assegurar os espaços dialogais para tornar viável uma organização social ${ }^{46}$. Ao se observar os modos de interação entre as pessoas, observa-se, nas palavras de Hespanha ${ }^{47}$ :

[...] (i) que normas são nela consensualmente reconhecidas como estipulando o que é o direito e (ii) a que instâncias ou instituições atribui ela, também consensualmente, a legitimidade para levar a cabo esse reconhecimento do direito. Nestes termos, o Estado perderia o papel de representante exclusivo da comunidade; talvez perdesse mesmo o papel de seu representante por defeito; Em vez dessa instituição, formal e definitiva, pelos processos da democracia representativa e do mandato político, de um porta-voz oficial e exclusivo para declarar o direito, a comunidade reservaria para ela, embora por intermédio de distintas instituições e processos, esse reconhecimento, fazendo isso no próprio curso da vida.

Qualquer ambiente democrático regulado por leis não denota tão somente a vontade das pessoas pelo Estado e seus instrumentos formais de legitimação dessas aspirações. A elaboração de um direito das culturas reivindica participação, cooperação, responsabilidade, respeito na condução da vida cotidiana. Cada pessoa, no seu agir diário, é um intérprete daquilo que dispõe as normas

Pluralismo jurídico e direito democrático. São Paulo: Annablume, 2013. p. 119.

46 HESPANHA, Antônio Manuel. Pluralismo jurídico e direito democrático. São Paulo: Annablume, 2013. p. 119.

47 HESPANHA, Antônio Manuel. Pluralismo jurídico e direito democrático. São Paulo: Annablume, 2013. p. 119. jurídicas - especialmente as constituições ${ }^{48}$ - ou os próprios costumes e modifica, aperfeiçoa, complementa os seus significados.

Os desafios multiculturais, as suas dificuldades, as privações, as desigualdades deverão indicar como a democracia se torna necessária para que haja condições de se escolher e decidir propostas hábeis à qualificação $\mathrm{e}$ melhoria desse espaço. As pessoas encontram as respostas para organizarem e preservarem os cenários de paz no dia a dia.

Trabalho idêntico se observa a partir do Poder Judiciário. As decisões proferidas nesses locais não podem representar simples abstrações, de pretensão universal e homogênea, como se identifica pelo aspecto pragmático da commom law ${ }^{49}$, mas pela preocupação argumentativa no sentido de buscar uma resposta para os cenários de fanatismo, intolerância, fome, miséria, exclusão, ou seja, tudo aquilo que não representa uma comunhão social, cultural e histórica para se consolidar o reconhecimento da paz pelo nosso vínculo antropológico comum.

A conquista de um direito das culturas por meio do Pluralismo Jurídico e do Multiculturalismo demonstra que existem diferentes locais de produção, interpretação e aplicação do Direito. Não se pode admitir que, num cenário democrático, a voz do Estado - e todos os seus procedimentos - sintetize o mosaico de ações e pensamento os quais habitam a pluralidade cultural, seja local ou global. A resposta pode ser demasiadamente "simplista" e gerar indiferenças, ressaltar falsas solidariedades, intensificar as fatalidades que eliminam os seres humanos todos os dias.

48 "Se se quiser, tem-se aqui uma democratização da interpretação constitucional. Isso significa que a teoria da interpretação deve ser garantida sob a influência da teoria democrática. Portanto, é impensável uma interpretação da Constituição sem o cidadão ativo e sem as potências públicas [...]. Todo aquele que vive no contexto regulado por uma norma e que vive com este contexto é, indireta ou, até mesmo diretamente, um intérprete dessa norma". HÄBERLE, Peter. Hermenêutica constitucional: a sociedade aberta dos intérpretes da constituição: contribuição para a interpretação pluralista e rocedimental da constituição. Porto Alegre: Sérgio Antonio Fabris, 1997, p. 14-15.

49 "A racionalidade que, nesta situação, deve guiar as Cortes, não pode ser aquela pragmática da commom law. Isto é, não pode basear-se sobre a sua correspondência a um logos transcendente ou imanente, mas pode fundar-se somente sobre a comunhão social acerca da razoabilidade histórica das soluções concretas singulares". SANTORO, Emílio. A democracia é ainda adaptável às sociedades multiculturais? In: FREITAS, Juarez; TEIXEIRA, Anderson V (Orgs.). Direito à democracia: ensaios transdisciplinares. São Paulo: Conceito, 2011. p. 5-281. p. 106. 
Ao Estado cabe reconhecer várias instâncias que oportunizam os debates públicos para a melhoria da Democracia e do Direito. Na medida em que vários sujeitos - estatais e não estatais - participam e cooperam para mitigar as acentuadas desigualdades produzidas por ações globais ou locais, percebe-se um esforço para se identificar o que torna legítimo e viável a convivência nesse contexto multicultural e complexo. Por esse motivo, o Pluralismo Jurídico não visa eliminar fontes de criação do Direito, mas enfatizar a natureza complementar entre todas dentro de um cenário democrático.

Não obstante, é necessário identificar, nos diferentes matizes culturais, o que torna legítimo a convivência no tempo e espaço. Não existe dignidade como critério abstrato e universal. Essa dimensão surge pelas adversidades, pelas tensões entre as culturas no dia a dia. É nesse local que a responsabilidade e cooperação ganham contornos e formas para permitir ao Direito - seja no seu sentido cultural ou normativo - cumprir a sua função social de organizar as interações humanas e preservá-las contra aquilo que as elimine.

Por esse motivo, o Pluralismo Jurídico admite, sim, a existência de outros locais, outros saberes, outras responsabilidades as quais conduzem ao reconhecimento, ao respeito pelos inúmeros talentos que habitam o mundo. Entretanto, não significa que todos tenham capacidade para estimular e assegurar cenários de paz. A vivência por meio das privações, das perdas, das desigualdades sem fronteiras torna claro os seus limites, bem como estimula a necessidade por uma Justiça que, pela sua definição, deve ser igualmente plural.

\section{Considerações finais}

As diferentes particularidades históricas e culturais que se observam no mundo evidenciam como a vida local se torna o único espaço de compreensão sobre a importância da pluralidade de cenários, de diálogos, de erros, de acertos que constituem o nosso devir utópico para o desvelo desse nosso destino de humanidade. Em cada região, em cada relação humana, em cada tentativa de ampliar os horizontes culturais, há condições para se identificar novos conteúdos os quais asseguram a inovação da Democracia no tempo, bem como a produção, interpretação e aplicação de regas que preservem esses cenários. consegue reconhecer essa pluralidade cultural, tampouco visualiza como os diferentes matizes da vida local cotidiana são capazes de trazerem respostas satisfatórias para os desafios - especialmente normativos - deste século XXI. A inspiração para uma organização social justa e ética não é proveniente da infalibilidade, da força do Estado, mas de como as diferenças humanas convergem para estimular ações tolerantes, solidárias, comunitárias a fim de proporem sentidos cada vez mais próprios da época que vivem.

Por esse motivo, não é possível que os limites fronteiriços do Estado nacional sufoquem a dinâmica de valores e culturas as quais convivem numa dimensão local. Esse é o elogio que se faz à diversidade. Num mundo de rápidas informações e comunicações, a vida cotidiana se torna global. Esse localismo global denota como é possível encontrar diferentes respostas para diferentes interesses, a fim de assegurar não apenas o exercício de procedimentos democráticos, mas, principalmente, aquilo que se torna indispensável, comum para que todos tenham qualidade de vida.

O Pluralismo Jurídico, aliado à concepção do Multiculturalismo, demonstra a necessidade de se reconhecer, especialmente ao Direito, as práticas, as culturas e os locais que, pelos seus consensos ou dissensos, promovem novos sentidos para o aperfeiçoamento da convivência, o esclarecimento sobre o exercício da Liberdade e Igualdade diante de violências como a miséria, a fome, o encobrimento do Outro (ou a sua eliminação) por não pertencer a um determinado status político, cultural ou econômico, o cerceamento abusivo de liberdades por entidades estatais, entre outros fenômenos.

Sabe-se, por meio do Pluralismo Jurídico, que os discursos enunciados pelas normas jurídicas, principalmente a Constituição, não exaurem - ou sequer reconhecem - essa multiplicidade de manifestações de valores globais nos limites espaciais da vida cotidiana. Numa sociedade aberta e pluralista, a participação de todos em diferentes situações propõe esclarecimentos necessários sobre como se torna possível materializar condições de Justiça. É a vida comum, catalisada pelos direitos, a fonte de resolução dos conflitos humanos a qual deve inspirar o Direito a ser, igualmente, aberto, dialogal e plural.

$\mathrm{Na}$ medida em que as sociedades se tornam mais complexas, mais dinâmicas, mais interativas, surgem novos desafios e novos sujeitos os quais demandam espaços de participação. A consolidação da Democracia conduz 
à formação de conhecimentos elaborados por um senso comum que evidencia as fragilidades de um único $a u$ tointeresse identificado como vontade geral. Os desafios, as dificuldades, os dissensos que ocorrem todos os dias possibilitam identificar, compreender e exercitar novos critérios éticos, políticos e estéticos a fim de oportunizar os elementos cartográficos da nossa convivência.

É esse grau de complementaridade entre as diferentes culturas, os pontos de convergência para estimular os cenários pacíficos, o reconhecimento da importância das particularidades criadas no decorrer da História, a necessidade de se repensar a produção, interpretação e aplicado do Direito numa era global e plural que o grupo de pesquisa "Multiculturalismo e Pluralismo Jurídico" do Complexo de Ensino Superior Meridional - IMED se propõe a refletir acerca dos cenários mundiais e suas dificuldades no sentido de elaborar respostas as quais sejam democráticas, abertas e plurais.

Os estudos e pesquisas realizados tentam não apenas esclarecer como se torna possível ampliar os espaços democráticos e mecanismos de efetivação da Justiça, mas, principalmente, quais são as condições para se mitigar as profundas misérias humanas, as desigualdades econômicas e de gênero, a sobreposição de culturas para se eliminar outras, a indiferença global e as irresponsabilidades criadas - e estimuladas - por interesses que optam não participar de um cenário mundial cada vez mais interdependente. $\mathrm{O}$ estímulo para relações humanas mais solidárias e tolerantes somente ocorre por meio de nossas experiências históricas nas múltiplas culturas que habitam o mundo.

A Justiça é o vetor de orientação para o cumprimento dos objetivos sociais do Direito. Nenhum desses dois fenômenos privilegia interesses pessoais ou de grupos ao diálogo entre a pluralidade de manifestações culturais. Por esse motivo, as respostas para identificar, compreender, exercitar e reconhecer a Liberdade, a Igualdade, a Solidariedade, a Fraternidade, a Democracia surge pela Alteridade. É a partir dessa situação, é a partir do Outro que todos esses critérios se tornam indispensáveis para qualquer projeto de civilização no decorrer do tempo. As nossas respostas são plurais e não individuais ou uníssonas pela voz do Estado nacional.

\section{Referências}

AQUINO, Sérgio Ricardo Fernandes de. $O$ direito em busca de sua humanidade: diálogos errantes. Curitiba: CRV, 2014.
ARNAUD, André-Jean. $O$ direito entre modernidade e a globalização: lições de filosofia do direito e do Estado. Rio de Janeiro: Renovar, 1999.

ARNAUD, André-Jean; JUNQUEIRA, Eliane Botelho. Dicionário da globalização. Rio de Janeiro: Lumen Juris, 2006.

CUNHA, Paulo Ferreira da. Breve tratado da (in)justiça. São Paulo: Quartier Latin, 2009.

DALANEZE, Sérgio. Contribuição do pluralismo no debate das ideias jurídicas. In: WOLKMER, Antonio Carlos; VERAS NETO, Francisco Q.; LIXA, Ivone M. (Orgs.). Pluralismo jurídico: os novos caminhos da contemporaneidade. São Paulo: Saraiva, 2010. p. 7-342.

DEMO, Pedro. Éticas multiculturais: sobre a convivência humana possível. Petrópolis, RJ: Vozes, 2005.

DIAS, Maria da Graça dos Santos. Sociedade. In: BARRETO, Vicente de Paulo. Dicionário de filosofia política. São Leopoldo: UNISINOS, 2010. p. 9-553.

GIAMBIAGI, Fabio; BARRO, Octavio de. Brasil globalizado. 3. ed. Rio de Janeiro: Elsevier, 2008.

HÄBERLE, Peter. Hermenêutica constitucional: a sociedade aberta dos intérpretes da Constituição - contribuição para a interpretação pluralista e "procedimental" da Constituição. Porto Alegre: Sérgio Antonio Fabris, 1997.

HESPANHA, Antônio Manuel. Pluralismo jurídico e direito democrático. São Paulo: Annablume, 2013.

MELO, Osvaldo Ferreira de. O papel da política jurídica na construção normativa da pós-modernidade. In: DIAS, Maria da Graça dos Santos; MELO, Osvaldo Ferreira de; SILVA, Moacyr Motta da (Orgs.). Política jurídica e pós-modernidade. Florianópolis: Conceito, 2009. p. 9-236.

MORIN, Edgar. O método 6: ética. Porto Alegre: Sulina, 2005.

PASOLD, Cesar Luiz. Metodologia da pesquisa jurídica: teoria e prática. 12. ed. São Paulo: Conceito, 2011.

RAWLS, John. O direito dos povos. São Paulo: Martins Fontes, 2001.

REALE, Miguel. O direito como experiência: introdução à epistemologia jurídica. São Paulo: Saraiva, 2010.

RICOEUR, Paul. O justo 1: a justiça como regra moral e como instituição. São Paulo: Martins Fontes, 2008.

RIFKIN, Jeremy. La civilización empática: la carrera hacia una conciencia global en un mundo en crisis. Traducción de Genís Sánchez Barberán y Vanesa Casanova. Barcelona: Paidós, 2010. 
SANTORO, Emílio. A democracia é ainda adaptável às sociedades multiculturais? In: FREITAS, Juarez; TEIXEIRA, Anderson V (Orgs.). Direito à democracia: ensaios transdisciplinares. São Paulo: Conceito, 2011. p. 5-281.

SANTOS, Boaventura de Sousa. A crítica da razão indolente: contra o desperdício da experiência. 5. ed. São Paulo: Cortez, 2005. v. 1.

SENNET, Richard. Respeito: a formação do caráter num mundo desigual. Rio de Janeiro: Record, 2004.

TAYLOR, Charles. Multiculturalismo. Lisboa: Instituto Piaget, 1994.
WALZER, Michael. Esferas da justiça: uma defesa do pluralismo e da igualdade. São Paulo: Martins Fontes, 2003.

WOLKMER, Antonio Carlos. Pluralismo jurídico: fundamentos de uma nova cultura no direito. 3. ed. São Paulo: Alfa-Omega, 2001.

ZAMBAM, Neuro José. Amartya Sen: liberdade, justiça e desenvolvimento sustentável. Passo Fundo: IMED, 2012.

ZAMBAM, Neuro José; AQUINO, Sérgio Ricardo Fernandes de. Tolerância: reflexões filosóficas, políticas e jurídicas para o século XXI. Revista da AJURIS, Porto Alegre, v. 142, n. 137, mar. 2015. Disponível em: <http:// www.ajuris.org.br/OJS2/index.php/REVAJURIS/article/ view/389/323>. Acesso em: 22 fev. 2014. 